This item was submitted to Loughborough's Institutional Repository (https://dspace.lboro.ac.uk/) by the author and is made available under the following Creative Commons Licence conditions.

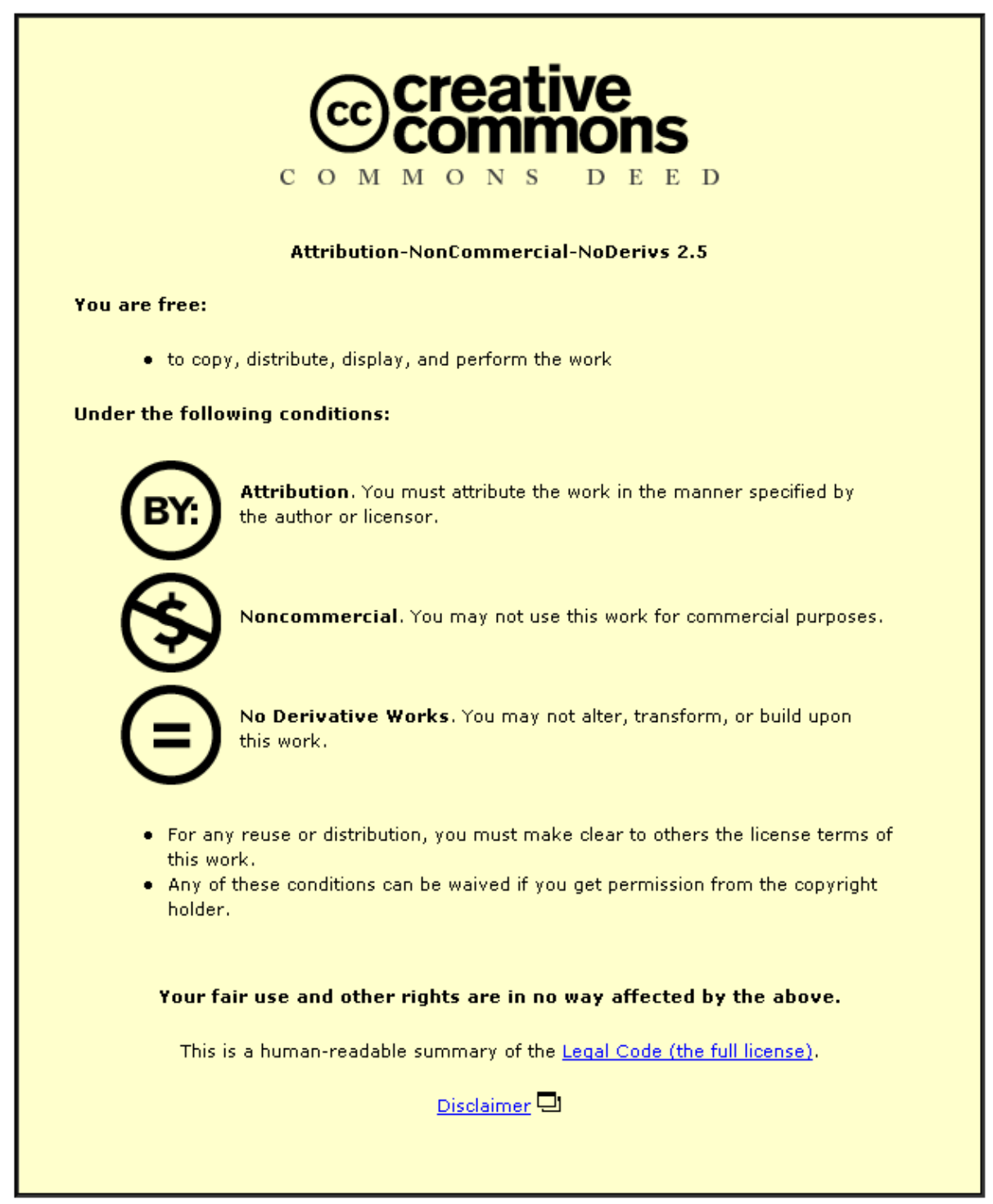

For the full text of this licence, please go to: http://creativecommons.org/licenses/by-nc-nd/2.5/ 


\title{
Current Leakage Failure of Conformally Coated Electronic Assemblies
}

\author{
Guangbin Dou*, D. Patrick Webb ${ }^{\#}$, David C. Whalley", David A. Hutt" and Antony R. Wilson ${ }^{\#}$ \\ d.p.webb@lboro.ac.uk; g.dou@imperial.ac.uk \\ *Electrical and Electronic Engineering, Imperial College, London, United Kingdom, SW7 2BT \\ ${ }^{\#}$ Wolfson School of Mechanical and Manufacturing Engineering, Loughborough University, Loughborough, Leicestershire, \\ United Kingdom, LE11 3TU.
}

\begin{abstract}
Conformal coatings are widely used on circuit board assemblies as an attempt to improve reliability and to ensure high insulation impedances, which are for example demanded by low current consumption battery operated RF circuitry. However, components, such as small ceramic capacitors, have occasionally been found to fail in some applications, particularly when covered with a thick silicone conformal coating. This is thought to be due to the diffusion of water through the coating to the capacitor surface where it then combines with solder flux residue, or other organic or ionic contamination left on the components, thereby dramatically increasing the effective component leakage current. The primary objective of this experimental research is therefore to establish a clear understanding of the effects of moisture exposure on the surface insulation resistance (SIR) of conformally coated printed circuit board (PCB) assemblies. This has been achieved through leakage current measurements on multilayer ceramic capacitors during storage in an environmental chamber during testing similar to IPC standards for non-component loaded boards.
\end{abstract}

\section{Introduction}

Over recent years there has been exponential growth in radio frequency (RF) technologies such as mobile communications, data transfer via RF transmission, wireless computer connectivity, remote sensing and autoidentification and data capture (AIDC) [1,2]. Such wireless enabled applications are inherently linked to operation in harsh environments, since the in-service conditions of a mobile device cannot be specified as tightly as for a fixed device. This typically leads to the use of conformal coatings on circuit board assemblies as an attempt to improve reliability and to ensure the high insulation impedances demanded by the low current consumption battery operated RF circuitry often used in such applications [3-5].

For high frequency devices, the required impedance of the circuit may become close to that of the circuit isolation offered by typical printed circuit board (PCB) assembly materials. High impedance insulation is also essential to achieving the intended battery lifetime in low maintenance applications, such as in the major growth area of wirelessly accessed sensor modules. Maintaining a low current draw in the quiescent state can yield operation lifetimes of up to ten years without battery replacement. Such modules are a versatile and costsaving alternative to hard wired sensors, and particularly attractive for locations where access for maintenance is difficult.

However, components such as small ceramic capacitors have occasionally been found to appear to fail in some applications, particularly when covered with a thick silicone conformal coating. This is thought to be due to the diffusion of water through the coating to the capacitor surface where it then combines with solder flux residue, or other organic or ionic contamination left on the components [6]. These effects are exacerbated by the widespread use of no clean pastes. No clean pastes are designed to passivate any corrosive soldering residues remaining after reflow, by encapsulation in an organic matrix which is soft enough to allow pin probe testing. However non-removal or incomplete removal of this organic material can inhibit adhesion and hence performance of a subsequently applied conformal coating. Osmotic pressure and water diffusion as described above can cause further delamination of the coating and spreading of the electrolyte, increasing the chances of contact with live electrical surfaces, creation of a galvanic cell and formation of a current leakage path. The mechanism is illustrated in Figure 1.
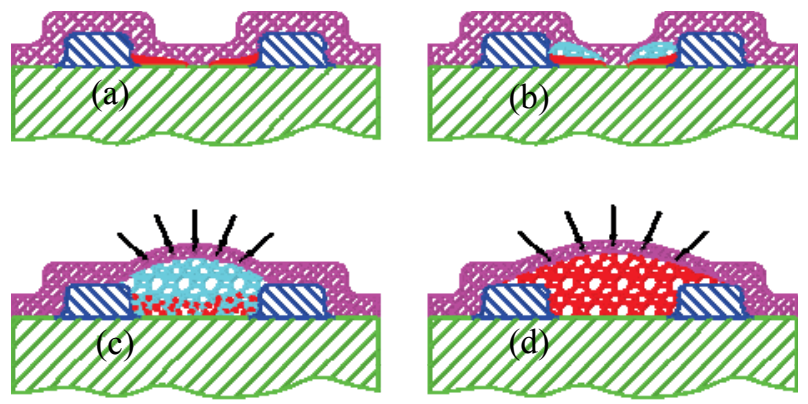

\section{Conformal coating;}

NV Conductor tracks;

\section{Fhux resictue or ionic comtemminution;}

DC. PCB or component body,

Osmotic pressure;
एक्? Water,

F. Electrolyte.
Figure 1. Potential failure mechanism: (a) Conformal coating covering soldering residue on a component, (b) diffusion of water through conformal coating to near component surface, (c) delamination of conformal coating and formation of fluid filled vesicle due to osmotic pressure, (d) formation of electrolyte and current leakage path between conductor tracks.

Note that where in the past the chief cause of concern, when a galvanic cell is formed, is the possibility of the growth of metal dendrites which can short out conductor 
tracks, in the context of wireless devices the leakage current passed by the galvanic cell may be large enough to directly impair circuit functioning or reduce battery life. Such impairments may be hard to detect in the field as it is a soft failure, i.e. reduced performance, rather than a hard failure, i.e. cessation of function.

Although the authors are aware of instances of significant financial losses due to field failures attributed to comprised dielectric impedances, verification of the failure mechanisms can be difficult as the presence of moisture may be transient. The authors have not been able to identify any published research specifically investigating such failures in relation to conformally coated surface mounted components.

Furthermore, soldering fluxes typically contain significant amounts of polyethylene glycol (PEG) or polypropylene glycol (PPG), which can be difficult to be completely removed/cleaned if they have been absorbed into the substrate [7]. SIR values can be dramatically compromised due to these flux residues remaining in the board [8-10].

The experimental programme reported here aimed to establish a clearer understanding of the effects of moisture exposure on the surface insulation resistance (SIR) of conformally coated PCB assemblies. The programme involved leakage current measurements on multilayer ceramic capacitors during storage in an environmental chamber under conditions and protocols similar to widely accepted IPC (Association Connecting Electronics Industries) standards [11] for boards not carrying components.

\section{Materials and Methods}

A test board was designed to allow attachment of 22 off 0603 size $(1.5 \mathrm{~mm} \times 0.76 \mathrm{~mm}) 33 \mathrm{pF} \mathrm{C0G}$ multi-layer ceramic chip capacitors (MLCCs). These were connected in parallel during testing, but individual component measurements were also possible to allow isolation of any failures. In order to provide a benchmark for the leakage level through the capacitors, IPC type IPC-B-24 SIR comb patterns were also placed on the same PCB. These boards were assembled using a commercially available, no clean flux tin-lead solder paste. The solder paste was first applied onto the PCBs using a DEK 260 stencil printing machine. The capacitors were then placed on the PCBs using a manually guided component placement machine, before they were reflowed using the solder paste manufacturer's recommended temperature profile. Figure 2 shows an assembled test board connected with an electrical monitoring circuit interface board to allow automated monitoring. Two batches of PCBs were assembled and damp heat tested. The first batch of boards were tested uncleaned and without encapsulation to investigate the effect of processing conditions on the performance in the test. The second batch of boards were cleaned to varying degrees in a spray-in-air machine using a commercial PCB cleaning fluid (Vigon A200), and were then encapsulated to investigate the effect of degree of surface contamination on the effectiveness of the encapsulation.

The process variables employed in the first batch were stencil aperture size (standard or oversize) and number of reflow cycles (one or two). The oversize apertures were intended to result in excess solder paste on the board and larger amounts of soldering residues. The second reflow cycle was intended to identify whether burning on of residues occurs. Four sets of three boards were assembled as listed in Table 1.

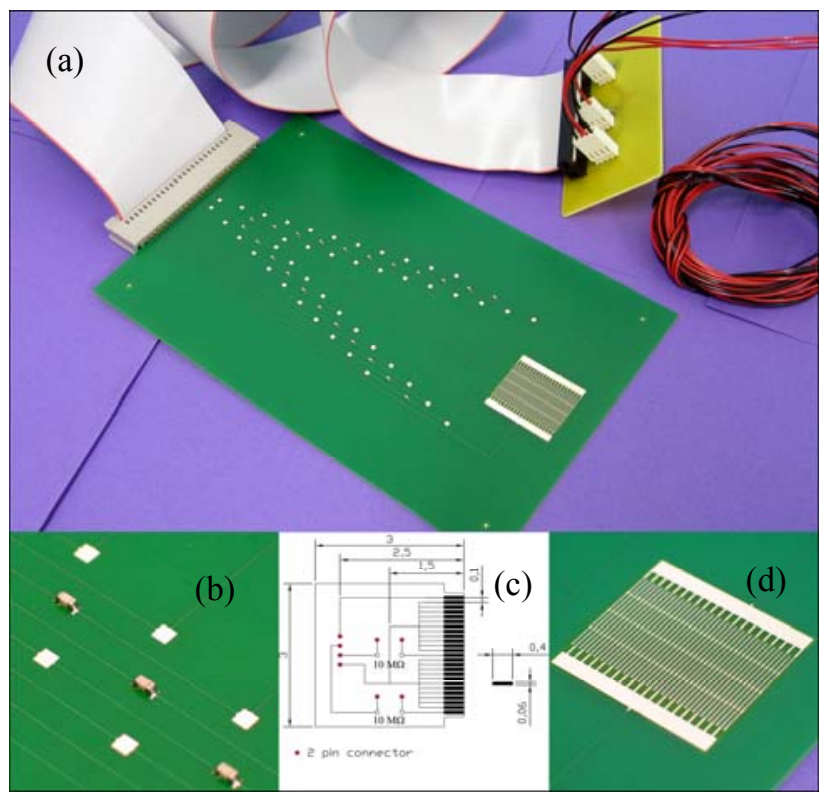

Figure 2. (a) An assembled test board connected with an external monitoring circuit interface board, (b) capacitors assembled on test board, (c) layout schematic for interface board, (d) SIR comb on test board.

In the second batch, PCBs were printed with the standard aperture size, given a single reflow and then cleaned. Batches of four boards at four levels of cleaning as listed in Table 2 were prepared. An ionic contamination measurement was used to characterise the cleaning levels, consisting of exposing the boards to a $75 \%$ solution of 2-propanol in de-ionised water, and measuring the change in conductivity of the solution. The change in conductivity is expressed in units of $\mu \mathrm{g} \mathrm{NaCl}$ equivalent $/ \mathrm{cm}^{2}$, signifying the mass of $\mathrm{NaCl}$ required to be dissolved in the solution to achieve the same change in conductivity, divided by the area of the board. Following cleaning two boards from each cleaning level were coated with a silicone gel (Dow Corning Tough Gel) to a thickness of about $5 \mathrm{~mm}$ (except cleaning level I for which only one board was coated ). The gel was supplied in two parts. These were mixed in a volume ratio of $1: 1$ by syringe dispensing through a mixing nozzle onto the samples. Dams made from acrylic plastic sheet were used to retain the gel during cure for 24 hours at room temperature. The coated boards were then damp heat tested along with an uncleaned board left unencapsulated as a control. 
Table 1: First batch processing parameters

\begin{tabular}{|c|c|}
\hline Sample code & Process \\
\hline O2 & Oversize apertures, two reflows \\
\hline O1 & Oversize apertures, one reflow \\
\hline S2 & Standard apertures, two reflows \\
\hline S1 & Standard apertures, one reflow \\
\hline
\end{tabular}

Table 2: Second batch samples

\begin{tabular}{|c|c|c|}
\hline $\begin{array}{c}\text { Cleaning } \\
\text { level }\end{array}$ & $\begin{array}{c}\text { Cleaning process } \\
\text { (followed by water } \\
\text { rinsing and air } \\
\text { drying) }\end{array}$ & $\begin{array}{c}\text { Measured ionic } \\
\text { contamination } \\
(\mu \mathrm{g} \mathrm{NaCl} \text { eq./ } \\
\left.\mathrm{cm}^{2}\right)\end{array}$ \\
\hline Level I & Uncleaned & 0.24 \\
\hline Level II & $\begin{array}{c}\text { with Vigon } \mathrm{A} 200, \\
0.5 \mathrm{~min}, 20^{\circ} \mathrm{C}\end{array}$ & 0.08 \\
\hline Level III & $\begin{array}{c}\text { with Vigon } \mathrm{A} 200, \\
1 \mathrm{~min}, 20^{\circ} \mathrm{C}\end{array}$ & 0.07 \\
\hline Level IV & $\begin{array}{c}\text { with Vigon } \mathrm{A} 200, \\
10 \mathrm{~min}, 50^{\circ} \mathrm{C}\end{array}$ & 0.07 \\
\hline
\end{tabular}

All the damp heat tests lasted 168 hours and were carried out in an environmental test chamber (Delta $190 \mathrm{H}$ ) at conditions of $85 \% \mathrm{RH}$ (relative humidity) and $85^{\circ} \mathrm{C}$. During the tests, a computer controlled Agilent 34970A Data Acquisition system was used to monitor the leakage currents using the monitoring circuit shown in Figure 3. A forward bias of $5 \mathrm{~V}$ was applied to the capacitors and $25 \mathrm{~V}$ to the comb pattern for most of the $168 \mathrm{~h}$ and the leakage currents were measured every 10 minutes. At the beginning of the test, at 24 hours, 96 hours, and at the end of the test, a reverse bias of $10 \mathrm{~V}$ was applied to the capacitors and $50 \mathrm{~V}$ to the comb pattern and the leakage current monitored for about 10 minutes before the forward bias was again applied. As specified in the IPC standard [11], the geometric mean of twelve resistance values was calculated for each set of reverse bias data. This geometric mean value was then multiplied by the number of capacitors (22) to give a resistance per capacitor. This resistance per capacitor is the quantity plotted in the graphs of reverse bias capacitor circuit resistance in the results section below.

\section{Damp Heat Test Results}

The average reverse leakage currents associated with the capacitors for the first batch, non-cleaned boards is shown in Figure 4. There is little difference at zero and 24 hours among the different process variations. At later times both extended heat reflow time and excess solder appear to increase the measured resistance compared to normative (standard aperture, single reflow) processing. The normative process parameters were therefore chosen for the second batch boards, to provide the worst case for testing of the performance of the conformal coating.

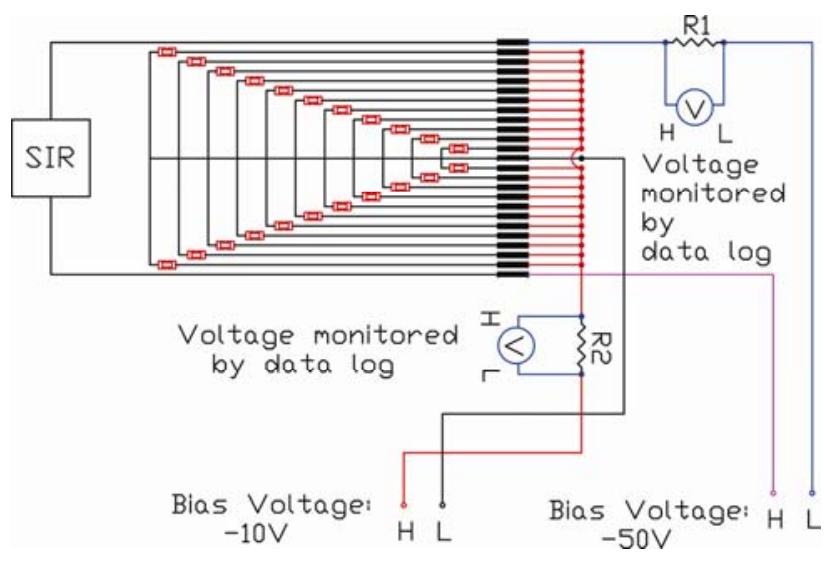

Figure 3. Circuit layout for damp heat test leakage current monitoring.

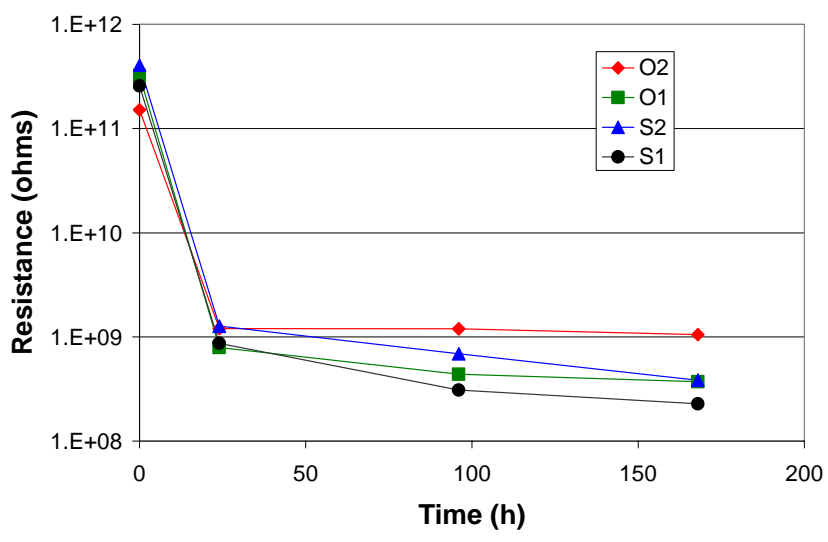

Figure 4. Damp heat test reverse bias capacitor circuit resistances for batch 1 .

The results of the damp heat test on the second batch of variously cleaned and encapsulated samples boards are shown in Figure 5. The initial resistances are strongly correlated with the cleaning level of the boards, with the most intense cleaning producing the highest resistance. It should be noted that this difference in performance occurs despite the ionic cleanliness ratings of the board surfaces at cleaning levels II, III and IV being indistinguishable as shown in Table 2. The initial resistances of the boards undergoing the less intense cleaning, levels II and III, and no cleaning at all (level I) when encapsulated exhibit lower resistances than the uncleaned, unencapsulated board. At 24 hours and subsequently the variation in the leakage resistance of the capacitor circuits drops to less than a factor of 1.4. The presence of the encapsulation makes almost no difference by 168 hours, when the variation is a factor of 1.1 .

The capacitor circuit resistance of the unencapsulated, uncleaned board is higher throughout the test than that of all except the level IV cleaned encapsulated boards. This can be seen more clearly in the forward bias data in Figure 6. It can also be seen that the unencapsulated board trace exhibits large fluctuations in resistance, possibly because it is more sensitive to minor changes in humidity than the encapsulated boards. 


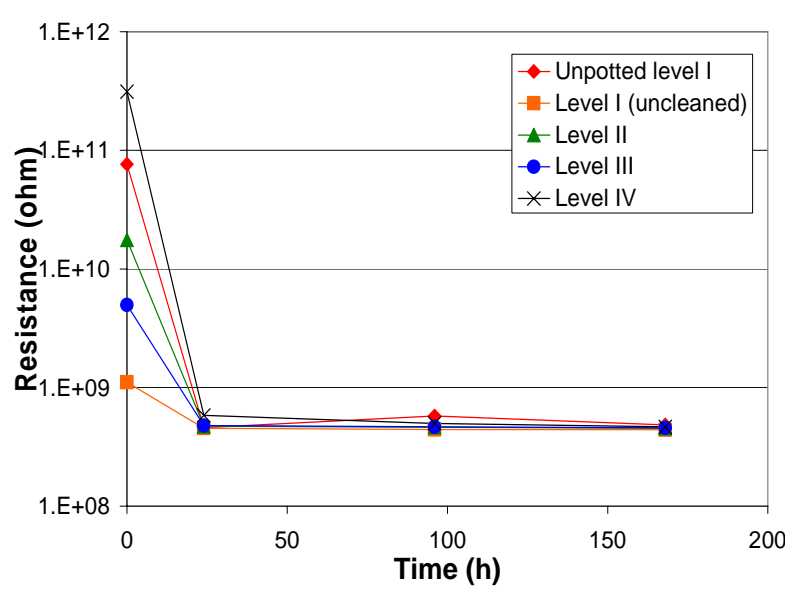

Figure 5. Damp heat test reverse bias capacitor circuit resistances for batch 2 .

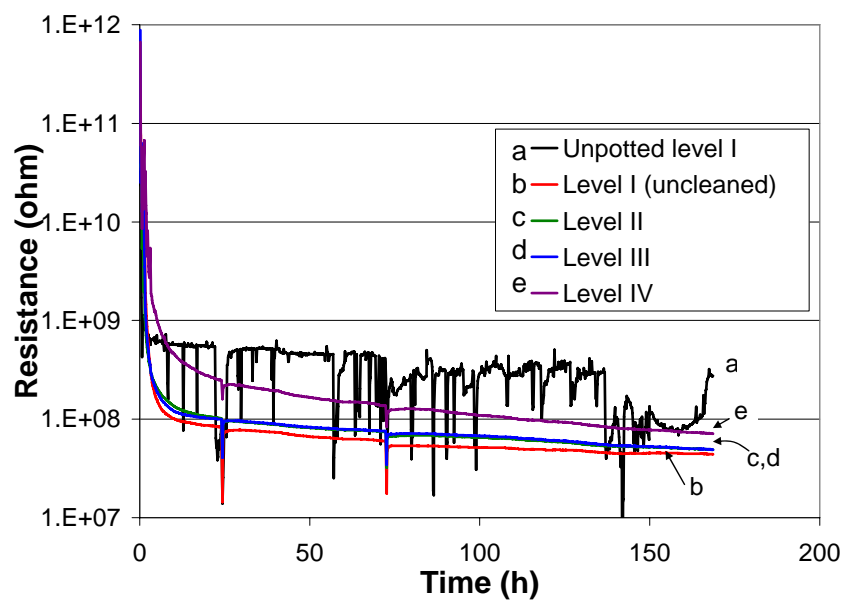

Figure 6. Damp heat test forward bias capacitor circuit resistances for batch 2 .

\section{Discussion and Other Results}

Although there is a systematic trend correlated with degree of cleaning in the capacitor performance in the damp heat tests, as shown in Figures 5 and 6, the most commonly used industry index of board cleanliness, i.e. the ionic contamination measurement, does not distinguish among the cleaning levels beyond level II. Therefore to correlate cleaning with the amount of process residue two qualitative methods of assessing board cleanliness, the Zestron Flux Test and the Zestron Resin Test were used. In both tests a colour reaction occurs in a liquid applied to the board in areas where the type of contamination being tested for is present. The flux test is sensitive to unreacted organic activators, and there were no colour changes observed for any of the cleaned boards (levels II to IV). The resin test results are summarised in Table 3, and indicated that the degree of resin on the capacitor surfaces is probably responsible for the capacitor performances in the damp heat tests.
Table 3. Characterisation of cleaning levels using resin test

\begin{tabular}{|c|c|c|}
\hline Cleaning level & $\begin{array}{c}\text { Colour changes } \\
\text { on capacitor top } \\
\text { surfaces }\end{array}$ & $\begin{array}{c}\text { Colour changes } \\
\text { on capacitor } \\
\text { solder joints }\end{array}$ \\
\hline I (uncleaned) & Yes & Yes \\
\hline II & Yes & Yes \\
\hline III & Some & No \\
\hline IV & No & No \\
\hline
\end{tabular}

The results of the resin test on an uncleaned capacitor can be seen in Figure 7, with the resin visible as a brown stain. The resin forms a characteristic hourglass shape extending from the metallisations at the ends of the capacitor across the insulative capacitor surface. It is speculated that ionic species may tend to accumulate at the edge of the resin meniscus as in a coffee cup stain effect, forming a bridge of contamination between the ends of the capacitor which is slightly harder to remove than the bulk of the resin. This suggestion is partly supported by the appearance of witness marks on some level IV cleaned capacitors, as shown in Figure 8.



Figure 7. Uncleaned capacitor after resin test. The resin is indicated by a brown stain.

Although contamination may also be present on the underside of the capacitors, and would not be revealed by the resin test, contamination on the top surface is more likely to interact with the encapsulation. Another factor which would make the capacitors harder to clean would be surface porosity. However no porosity was seen in high resolution scanning electron microscopy examination of a fracture surface cross-section of a capacitor. A typical image is shown in Figure 9. The grain structure of the ceramic can be clearly seen, with grain size of around $0.7 \mu \mathrm{m}$, and much smaller inter-grain pores. No inter-grain pores can be seen in the region near the surface to a depth of around $1 \mu \mathrm{m}$. A fracture surface was used as a cross-section because cutting and polishing may cause filling and obscuration of pores. 


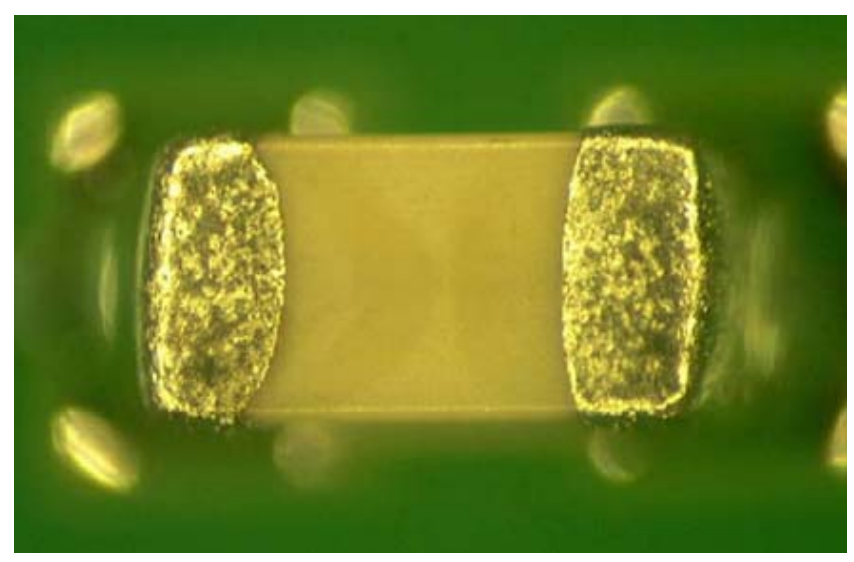

Figure 8. Level IV cleaned capacitor exhibiting contamination witness mark..

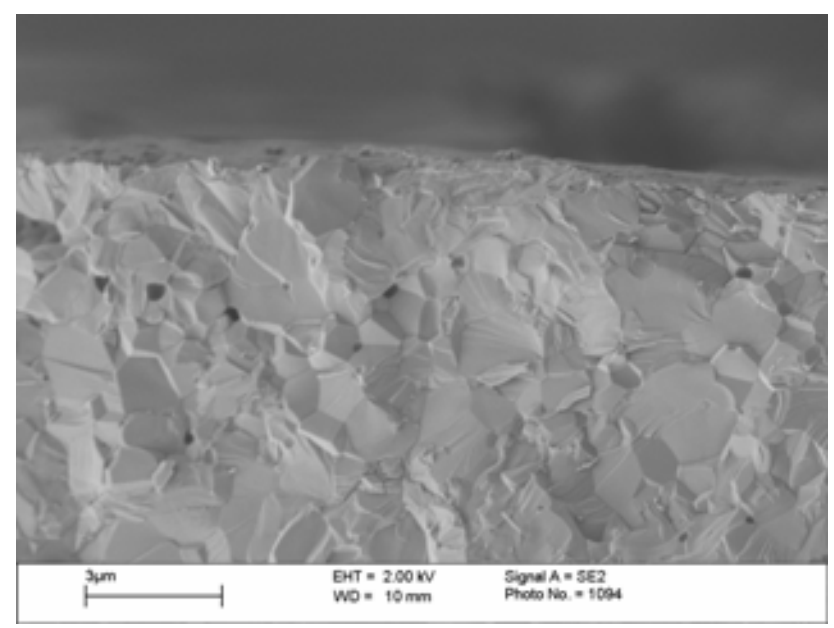

Figure 9. Scanning electron micrograph of fracture cross section of a capacitor near the surface.

Evidence of interaction between the encapsulant and surface contamination in the damp heat tests can be seen in Figure 10 showing discoloration of the reflowed solder on the bars of the comb on a level I (uncleaned) board. Discoloration is not seen on the comb on the unencapsulated level I board which went through the test as shown in Figure 11.

The surface condition of the as-received capacitors was investigated by the wetting angle method. The capacitors were examined directly after removal from the reel-type packaging. Figure 12 shows a droplet of deionised water on the ceramic surface of one of the capacitors. The high wetting angle indicates the presence of a low surface energy layer, possibly organic contamination. Bare ceramic would be expected to have a high surface energy and hence a low wetting angle.

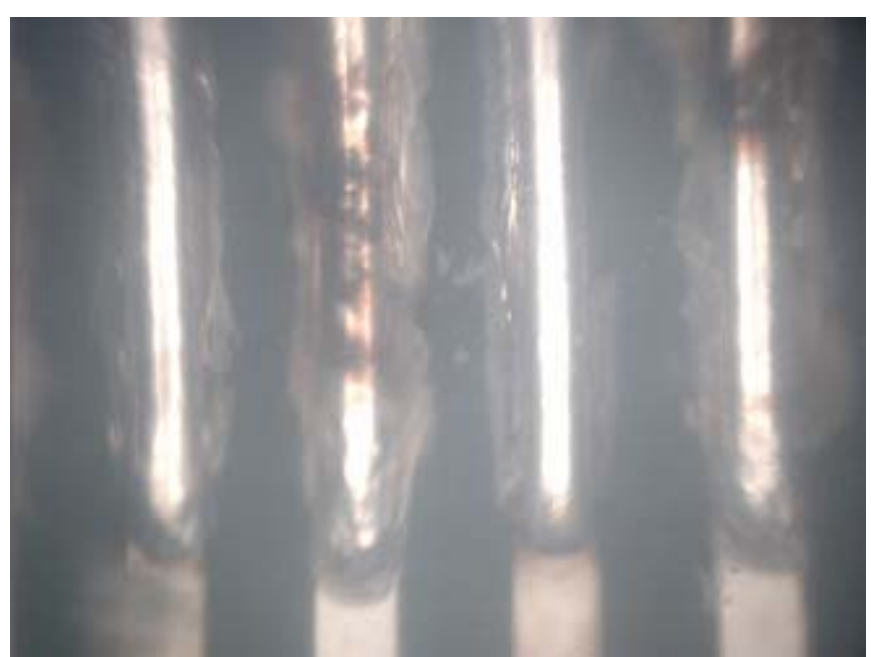

Figure 10. Discoloration on reflowed solder on comb bars on level I (uncleaned ) board after the damp heat test seen through the encapsulation.

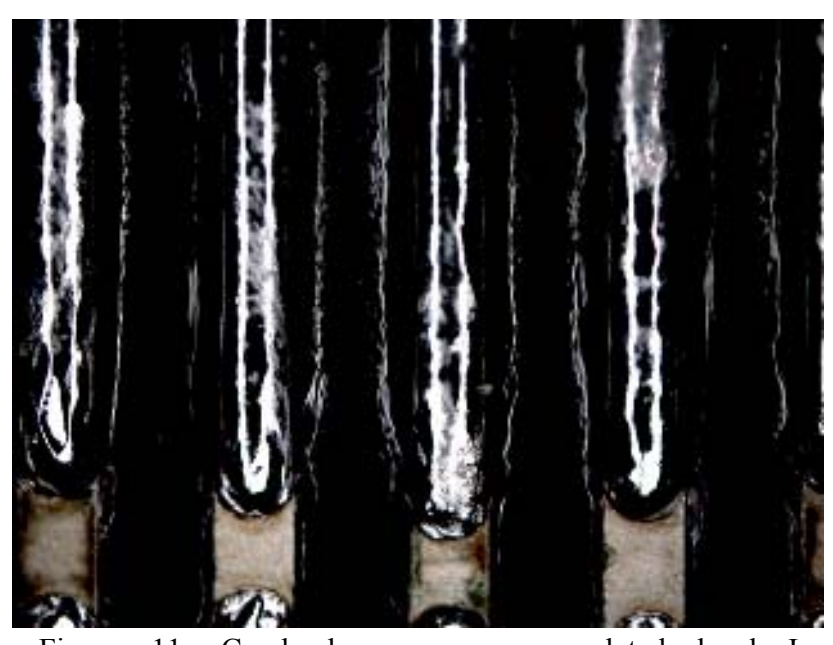

Figure 11. Comb bars on unencapsulated level I (uncleaned ) board after the damp heat test
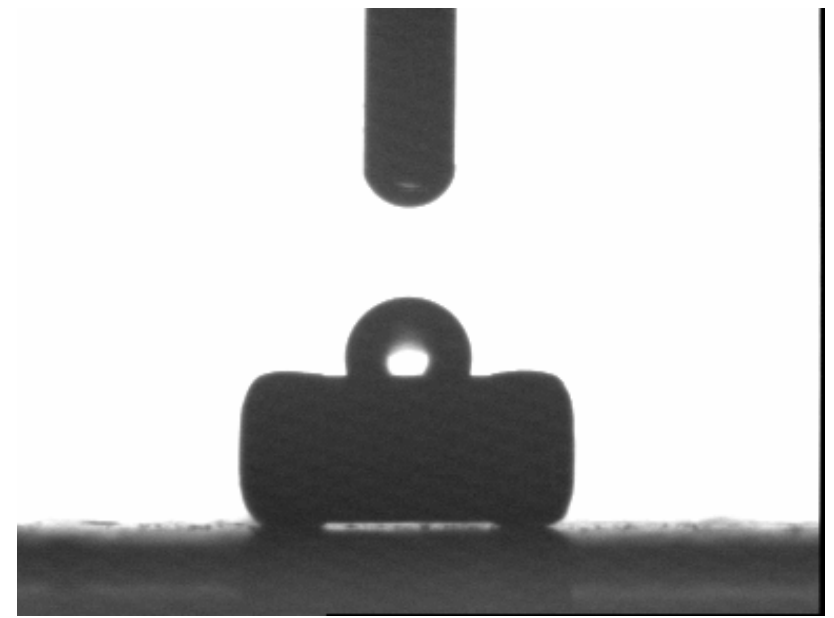

Figure 12. Water wetting angle on an as received capacitor. 


\section{Conclusions}

Damp heat insulation resistance measurements following a procedure similar to IPC standard surface insulation resistance (SIR) testing for non-component loaded boards have been carried out on capacitor loaded PCBs reflowed with a low-solids solder paste and encapsulated with a two-part silicone based conformal coating. The boards were cleaned to differing levels to allow investigation of the effect of degree of surface contamination on the effectiveness of the conformal coating. A difference in the capacitor circuit resistances was seen at short time in the tests correlated with the degree of cleaning. The differences were seen despite ionic contamination tests yielding similar or identical levels. A qualitative test for the presence of organic resin residues from soldering was found to be a better predictor of the behaviour in the damp heat test. Discoloration of solder on comb structures was seen on encapsulated boards after the damp heat tests but not on unencapsulated boards.

\section{Acknowledgements}

The authors would like to thank Zestron Europe for the board cleaning, board cleanliness assessments and the images in Figures 7 and 8 , and to acknowledge the support of Henkel Ltd. This work was funded by the Innovative electronics Manufacturing Research Centre (IeMRC).

\section{References}

1. Kitra, M.I., Panagamuwa, C., McEvoy, J.P., Vardaxoglou, J.C., James, J. R., "Low SAR Ferrite Handset Antenna Design," IEEE Transactions on Antennas and Propagation, Vol. 55 No. 4 (2007), pp. 1155-1164.

2. Carlsson, C. et al, "RF Transmission over Multimode Fibers using VCSELs-comparing Standard and HighBandwidth Multimode Fibers," Journal of Lightwave Technology, Vol. 22, No. 7 (2004), pp. 1694-1700.

3. Suppa, M., Schauer, C., "Thick film coating materials and fast conformal coating processes - a contradiction?," Proceedings of the $2^{\text {nd }}$ International IEEE Conference on Polymers and Adhesives in Microelectronics and Photonics, Hungary, June 2002, (2002), pp. 165-171.

4. Wu, J. et al, "Novel Bi-Layer Conformal Coating for Reliability Without Hermeticity MEMS Encapsulation," IEEE Transactions on Electronics Packaging Manufacturing, Vol. 22, No. 3 (1999), pp. 195-201.

5. Medgyes, B. K., Ripka, G., "Qualifying Methods of Conformal Coatings used on Assembled Printed Circuit Boards", Proceedings of the $30^{\text {th }}$ International Spring Seminar on Electronics Technology, Romania, May 2007, (2007) pp. 429-433.

6. Ellis, B. N., Cleaning and Contamination of Electronics Components and Assemblies, Electrochemical Publications Limited, Scotland (1986).
7. Brous, J., "Water-soluble Flux and Its Effect on Board Insulation Resistance", Electronic Packaging and Production, Vol. 21, part 7 (1981), pp. 79-87.

8. Sohn, J. E., "How Clean is Clean: Effect of No-clean Flux Residues and Environmental Testing Conditions on Surface Insulation Resistance," Proceedings of the Technical Program, Surface Mount International, San Jose, 1994, pp. 391-402.

9. Ellis, B. N., "Low Voltage Insulation Resistance Measurement of Printed Circuit and Its Implication," Circuit World, Vol. 14, No. 2 (1988), pp. 21-25.

10. Zou, L., et al, "Surface Insulation Resistance (SIR) Response to Various Processing Parameters," Soldering \& Surface Mount Technology, Vol. 11, No. 2 (1999), pp. 30-34.

11. IPC, IPC-9201 Surface Insulation Resistance Handbook, IPC, Northbrook, U.S.A., (1996). 